\title{
Chapter 4 \\ Post-transitional Demography and Convergence: What Can We Learn from Half a Century of World Population Prospects?
}

\author{
Maria Castiglioni, Gianpiero Dalla-Zuanna, and Maria Letizia Tanturri
}

\subsection{Introduction}

The search for a common path of development has always been present in demographic research, which in general is short on theory and rich in empirical observations and quantification (Thornton 2001). This is perhaps not surprising since demography is the field that has "produced one of the best documented generalizations in the social sciences: the Demographic Transition" (Kirk 1996: 361). This data-driven theory predicts a shared trajectory for all societies, whereby they experienced (or are now experiencing) a shift from an inefficient pre-modern regime of high mortality and high fertility to a post-modern equilibrium characterized by both low fertility and low mortality (Reher 2004, 2011; Livi Bacci 2012). The timing of this process differs across countries, such that its forerunners and latecomers can be identified, knowing that all nations will sooner or later undergo such a change (Reher 2004). Thanks to an impressive series of statistical regularities, for those countries that have begun the transition it is relatively simple to hypothesize a strong convergence in terms of future mortality and fertility trends. These basic elements of population forecasting thus see the eventual convergence of fertility and mortality rates for poor countries as an inevitable destiny, as has already occurred in rich countries.

What it is less clear, however, is what happens after the end of the Demographic Transition, when fertility is close to or under replacement level, infectious diseases are under control, and life expectancy at birth is above 65-70 years. As Reher (2019: 2) observes "after the great fall, fertility gave no indication of rebounding to even remotely similar levels to those holding during the peak of the baby boom" (see

M. Castiglioni $(\triangle) \cdot$ G. Dalla-Zuanna $\cdot$ M. L. Tanturri

Department of Statistical Sciences, University of Padova, Padova, Italy

e-mail: casti@stat.unipd 
also, Rindfuss et al. 2016; Billari 2018). Many scholars support the idea that the emerging disparities in the low fertility context are destined to persist (Rindfuss et al. 2016; Billari 2018; Rindfuss and Choe 2015, 2016). It seems, in fact, that developed countries may be on different paths with respect to fertility, aging, and migration, with potentially important consequences for future social and economic stability (Reher 2019; Anderson and Kohler 2015). Given such divergences, the task of population forecasting has become increasingly challenging, due also to the absence of strong theoretical models driving the hypotheses.

In what follows, we examine recent trends, assessing the supposition of a "weak convergence" in the aftermath of the Demographic Transition. That is, the notion that countries will converge towards similar fertility and mortality values and contained migration, with birth rates oscillating around replacement level, and as a result, the population growth rate of all countries will approach zero.

While this is far from a simple issue, we argue that it is extremely relevant for population forecasting, given that alternative hypotheses on fertility, mortality, and migration can result in very different population growth rates. Indeed, it is well known that seemingly small differences can have considerable consequences for both population dynamics and structures. For instance, consider a zero-migration stable population with a Total Fertility Rate (TFR) equal to 2.045 children per woman, a mean age at birth of 30 years and a sex ratio at birth of 104/100. A natural growth rate equal to zero can be achieved when mortality is low enough. A TFR of half a child less than replacement level $(\sim 1.5)$ implies that population will decrease at a rate of $1 \%$ a year. The decrease would be much stronger $(2.4 \%$ per year) if the TFR was just 1 child per woman (Kohler et al. 2002). ${ }^{1}$

Weak convergence is clearly the prevailing hypothesis in many of the UN World Population Prospects Revisions. Our aim here is to discuss this supposed convergence through an examination of the near past, comparing actual data with the forecasted fertility, mortality, and migration trends computed in the UN World Population Prospects over the last half century.

While the idea of comparing forecasted trends with real data is certainly not new (e.g. Preston 1974; Calot and Chesnais 1978; Keyfitz 1981; Stoto 1983; Pflaumer 1988; Keilman 1997, 1998, 2000, 2001; National Research Council 2000; Keilman and Pham 2004), our approach is unique in that we empirically test whether or not the convergence projected by the UN population forecasts is substantiated in the aftermath of Demographic Transitions. To this end, we examine the 38 countries that had already reached a TFR below 2.5 children per woman in the decade 1975 85 in order to assess whether or not the generalized expected weak convergence is empirically confirmed up until 2015.

\footnotetext{
${ }^{1} \mathrm{~A}$ growth rate close to zero, in the absence of migration, can be achieved even if TFR $<2$ and survival continues to improve (obviously with an aging population). As we will see in Sect. 4.2.4, this is precisely the population dynamic forecasted by the UN Population Prospects for the coming decades in countries where the TFR is currently less than 2.5 .
} 
The chapter is structured as follows. In Sect. 4.2 we review the literature relative to the notion of convergence and its alternative definitions. We then discuss the hypothesis that has driven different World Population Prospects Revisions, paying particular attention to the 2017 Revision for countries that at present have fertility levels lower than 2.5 children per woman. In Sect. 4.3, we describe the data and methods employed to conduct our comparisons. In Sect. 4.4, we compare demographic forecasts with actual patterns and present our results on fertility, mortality, and migration trends for the countries under analysis. In the final section, we discuss our results, which cast doubt on the idea of weak convergence.

\subsection{Background}

\subsubsection{Convergence vs. Divergence in Population Projections}

Demographic forecasts typically rely heavily on current vital statistics and extrapolate their trends into the future. They are rarely driven by behavioral sciences or strong theories that might help to deal with uncertainty. The most relevant exception consists of Demographic Transition regularities, which have aided forecasters in placing each country at a certain point along this well-known trajectory and in projecting future developments in light of that which has occurred in similar countries. That said, also along the Demographic Transition, relevant country/regional specificities can bias projections: the differences in the demographic transition features between more and less developed countries provide a particularly pertinent example to this regard (Livi Bacci 2012).

Establishing accurate hypotheses for population forecasts at the end of the Demographic Transition is even more complex due to a lack (or proved insufficiency) of strong theories that might help to predict demographic behaviors (e.g., the Second Demographic Transition Theory, or The New Household Economics Theory). Moreover, it is commonly accepted that uncertainty relative to population behavior is not only due to a dearth of scholarly knowledge, but is, in fact, inherent: individuals often make unpredictable choices in terms of family formation and childbearing, health-related behavior, and migration (Henry 1987; Keilman 2019). This seems particularly true as social constraints relax and the individualization of choices becomes the norm.

An extensive literature (Preston 1974; Calot and Chesnais 1978; Keyfitz 1981; Stoto 1983; Pflaumer 1988; Keilman 1997, 1998, 2000, 2001; National Research Council 2000; Keilman and Pham 2004) has endeavored to assess the accuracy of historical population forecasts by comparing them to observed statistics. Most studies focus on the accuracy of the size of the population and its growth. A complete and updated survey of previous work and its main inaccuracies in population forecasting is available in Keilman (2019). It is generally accepted that projection accuracy is better for shorter than longer durations, and for bigger as 
opposed to smaller populations. Previous research also shows that forecasts for the old and young tend to be less precise than those for intermediate age groups, as errors in mortality, fertility, and migration dynamics can significantly affect the size of these groups (Keilman 2019). In addition, it is well known that there is considerable variance in accuracy between regions; large bias can occur where (especially official) data are not reliable or available. Generally, scholars have shown that poor data quality worsens forecast performance. This relationship seems stronger for mortality than for fertility, and for short-term compared to long-term forecasts (Keilman 2019). Weak data on migration can also have a relevant impact on projection precision, particularly in countries where in-flows or out-flows are quantitatively relevant and protracted in time.

While much effort has been dedicated to evaluating the accuracy of demographic population forecasts in terms of population size, structure, and growth, to our knowledge only a handful of studies aim to test the hypothesis of long-run convergence in the aftermath of Demographic Transitions (Wilson 2011, 2013; Dorius 2008; Neumayer 2004). Our paper endeavors to fill this research gap.

Several instances of divergence in mortality trends have been illustrated in the demographic literature (Bloom and Canning 2007; Goesling and Firebaugh 2004; McMichael et al. 2004; Moser et al. 2005; Neumayer 2004). The spread of the HIV-AIDS epidemic in the 1990s, for example, brought the forecasted global mortality convergence observed in the 1980s to a halt (Neumayer 2004, Goesling and Firebaugh 2004; McMichael et al. 2004). Bloom and Canning (2007) show, with regard to the rise in life expectancy observed from 1963 to 2003, that a number of countries appear to have made the jump from the high-mortality cluster to the low-mortality cluster without a clear accompanying convergence. Their results suggest continuous advances among many countries within clusters, with rising life expectancy in some nations resulting in a shift from one cluster to the other. A related study, covering 195 nations during the period 1955-2005, reveals that while life expectancy averages converged across time, infant mortality rates instead continuously diverge; economic development improves life expectancy more than it reduces infant mortality, whereas the situation is reversed among wealthier nations (Clark 2011).

Though not always made explicit, a global fertility convergence is generally expected, with most countries following the path towards replacement fertility as projected by the Demographic Transition theory. Wilson (2001) provides an interesting empirical assessment of the extent to which the fertility revolution has become a worldwide phenomenon in the latter half of the twentieth century, within a "global demographic convergence" framework (both in terms of high life expectancy and low fertility). Yet the simple fact that now much of the world's population lives in countries or areas with below-replacement fertility does not necessarily mean that fertility rates are all destined to converge to the same level (Dorius 2008; Rindfuss and Choe 2015). Dorius (2008: 521), for example, argues that the observed intercountry variation in fertility decline from 1955 to 2005 "points to divergence, rather than convergence" and provides a robust convergence- 
divergence test of the magnitude and direction of change in fertility inequality, in contrast to that found several years earlier by Wilson (2001).

Recent studies of expert-based forecasts show that there is now less consensus among scholars on the future of fertility, particularly in countries having reached a TFR well below replacement level (Reher 2019; Basten et al. 2014; Rindfuss and Choe 2015, 2016; Rindfuss et al. 2016). More and more studies have begun to question the mainstream position of a long-term convergence to a same fertility level, both from a theoretical and an empirical perspective. Dorius (2008), cited above, highlights growth in fertility differences at the global level (including less and more developed countries). Meanwhile, Crenshaw et al. (2000) find divergence among less developed countries from 1965 to 1990. Casterline (2001) shows that the fertility transition has been highly unequal at the global level, with birth rates rising and falling over the second half of the twentieth century.

A focus on low fertility countries reveals a sort of bifurcation between countries where fertility has stabilized at relatively high levels (i.e., slightly lower than replacement level) and those where fertility has continued to decline to low or very low levels (less than 1.5) (Rindfuss and Choe 2015; Rindfuss et al. 2016). Sobotka (2017: S20) observes that period fertility rates usually continue to decrease - often to very low levels - even after replacement fertility has been reached, and that there is, in fact, "no obvious theoretical or empirical threshold around which period fertility tends to stabilize." The claimed reversals in reproductive behavior seem more an outcome of a "tempo effect" than a real change in behavior (Sobotka et al. 2017). Such views are in line with the work of Lutz et al. (2006) who envisage an inflection point when fertility is persistently lower than 1.5 children per woman, given that some forces (e.g., stable change in fertility ideals) may act as a "low fertility trap," impeding recovery. A similar result is also predicted by Reher (1998, 2019) who observes the emergence of distinct fertility regimes in post transition societies, along a divide between strong/weak family ties. Billari (2018) as well forecasts the persistence of fertility differentials among a selection of low fertility countries unless a number of conditions - that will not necessarily occur across the lowest-low fertility context - are met: a stronger position of young generations, a higher level of economic development and subjective well-being, and gender equity.

\subsubsection{Defining "Strong” (Beta) and "Weak" (Sigma) Convergence}

Economic forecasts have similarly been informed by the idea of convergence, particularly relative to levels of per capita income and product. Analysts have used a variety of statistical methods to test for such convergence within and between countries across a broad range of indicators and domains. One can distinguish between two types of convergence in growth empirics: beta-convergence and sigmaconvergence. 
According to Barro and Sala-i-Martin (1992), when partial correlation between growth in income over time and its initial level is negative, there is "betaconvergence," whereby the latter refers to a process in which poor regions grow faster than rich ones, and therefore catch up with the latter. The idea, as explained by Barro et al. (1991: 110), is that "the diminishing returns to capital set in slowly as an economy develops" and these automatic forces ensure convergence over time. In other words, "the condition where former laggards, fueled by higher growth rates, catch up with former leaders is referred to as beta-convergence because it is typically modeled using ordinary least squares regression where the annualized growth rate over the study period is regressed on the observed rate at base measurement" (Dorius 2008: 522; Barro et al. 1991; Barro and Sala-i-Martin 1992). Undoubtedly, demographic transition trends in life expectancy $\left(\mathrm{e}_{0}\right)$, infant mortality, and fertility provide excellent examples of beta-convergence (i.e., "strong convergence"). Here, considering various demographic measures, beta-convergence occurs when forerunners increase $\left(\mathrm{e}_{0}\right)$ or decrease $(\mathrm{TFR})$ slower than laggards; sigma-convergence occurs when cross-country variation in $\mathrm{e}_{0}$ or TFR decreases.

Behind this global trend, or reduction of cross-country variation over the long run (i.e., the strong convergence process), it is, however, also possible to observe sigmaconvergence when the dispersion of a measure (income per capita, in the previous example) around the average values falls over time (Dorius 2008). The standard deviation describes the overall spread of the fertility distribution (Sala-i-Martin 1996; Neumayer 2004). As Dorius (2008: 522) observes, "If the repeated crosssectional standard deviation increases, we conclude that countries are diverging on $\mathrm{Y}$ and if the variance declines, we conclude that countries are converging."

This standard deviation has been used to test for sigma-convergence in incomes (Sala-i-Martin 1996), infant and child survival rates, and life expectancy (Neumayer 2004; Dorius 2008), among other factors. The utility of the standard deviation in longitudinal designs is its ability to assess inequality under the condition of a relatively constant mean. Yet, as is well known, the TFR and life expectancy for the world have been anything but constant over recent decades. To this regard, Dorius (2008: 523) remarks that "When the mean of $\mathrm{Y}$ is trending down, the standard deviation might also be decreasing, but only if the standard deviation is decreasing faster relative to the mean is the fertility distribution becoming more equal". 2

The differences between the two measures should certainly be kept in mind when looking for sigma-convergence, in a world that is beta-converging.

\footnotetext{
${ }^{2}$ Sigma-convergence occurs when - in considering a group of countries - the mean of an indicator decreases less rapidly than its standard deviation. A good indicator of the sigma-convergence process is consequently the coefficient of variation (the ratio between the standard deviation and the arithmetic mean). In this chapter, we prefer to show parallel trends over time of both mean and standard deviation, as this allows to evaluate both components of the sigma-convergence.
} 


\subsubsection{Hypothesis of the UNPD World Population Prospects: A Review}

Between 1950 and 2017, the United Nations (UN) published a large set of population projections for the world, its major regions, and almost all countries. While the literature usually considers estimates for pre-transition countries to be problematic (Keilman 2001), it has now become of paramount importance to understand the reasoning behind UN Population Division (UNPD) experts' predictions of mortality, fertility, and migration for those countries that have already completed their Demographic Transition. Indeed, this is an increasingly relevant group. Keilman (2019) reports that data quality for Europe and North America is good, but forecasters' long-run projection of the age structure was inaccurate because they did not expect either the fall of fertility rates in the seventies, or the further increase in life expectancy. As a result, they overestimated the young component and underestimated the old one.

Rather than assess the degree of accuracy in estimating population size and structure (as done by Keilman 1998, 2001), in this chapter we focus on the hypothesis employed by the UNPD to carry out the four Revisions of the World Population Prospects in 1980, 1990, 2000, and 2017. Before turning to a comparison between their hypothesized trends and those actually observed, we briefly describe their assumptions and methods adopted. The World Population Prospects Revisions examined here have different projection horizons: 45 years for the 1980 Revision, 35 for the 1990 Revision, 50 for the 2000 Revision, and 85 for the 2017 Revision.

Until 2008, the UNPD adopted a deterministic scenario-based cohort component method to forecast world population. The approach has been criticized from a statistical point of view as uncertainty is not quantified and no probability is attached to the respective scenarios (usually high, medium, and low variants) (Alho and Spencer 1985; Lee 1998). Moreover, the scenario approach does not include all the different possible combinations of hypothesized mortality and fertility or migration. Indeed, a variant combination that is extreme for one variable is not necessary extreme for another. Moreover, a deterministic approach does not allow for the possibility of distinguishing between a random fluctuation and a structural one; for instance fertility may be high in 1 year due to a specific situation, but not in another (Keilman 2019; Bengtsson et al. 2019). In response to these limitations, the UNPD has adopted a stochastic Bayesian approach since the revision of 2012 (Raftery et al. 2012; UN 2014).

As the UNPD's approach has changed over time, so too have their expectations of fertility, mortality, and migration. With regard to the level of fertility, both the 1970 and 1980 Revisions forecast a decline as countries progress in economic and social development. The target being a TFR of 2.1, whereby countries with close but higher rates than this value will eventually reach replacement level and fertility stabilizes; conversely fertility is expected to rise and return to replacement level in those countries where it had fallen below this level. In 1990, the UNPD observed large variability in paths towards low fertility among developed countries, 
most of which remained below replacement level. Aware that in these countries trends in future fertility would be mostly affected by shifts in values and lifestyles, the UNPD incorporated hypotheses offered by national statistical offices (with some adjustments) so as to take into account country-specific value orientation and ideational changes. These were used to make medium, low, and high fertility assumptions. According to the three variants, TFR-targets in 2020-2025 were set at 1.9 children per woman in the medium variant, $2.25 \mathrm{c} / \mathrm{w}$ in the high variant, and 1.6 $\mathrm{c} / \mathrm{w}$ in the low variant. This approach was then abandoned in the subsequent World Population Prospects for the low fertility group, with TFR below replacement level in 2000. Countries were grouped by fertility levels around this year. Birth rates are forecasted to catch up in the 5-year period 2045-2050, close to the level of the 1960 cohort (if available), or to 1.7 for those registering a TFR of less than 1.5 in 2000, or to 1.9 for those with a TFR equal to or higher than 1.5 in 2000 . In all these approaches, sigma-convergence is assumed, and towards just one target value in the 1970, 1980, and 1990 Revisions, and two values, determined by previous fertility trends, in the following Revisions.

Since the 2012 Revision, the UNPD has adopted a probabilistic approach. In 2017, the general prediction was a convergence towards low fertility, although no specific numerical targets in the post-transition phase are presented. For low fertility countries that have completed the demographic transition, the UNPD estimates fertility change through a time series model, with the assumption that fertility fluctuates around country-specific levels based on a Bayesian hierarchical model (Raftery et al. 2014). The model is based on the specific history of the country and informed by empirical evidence from all low-fertility countries that have experienced fertility increases from a sub-replacement level, with the constraint that fertility cannot be higher than 2.1 births per woman. As the models are constructed relative to the particular experience of each nation, if the latter has experienced extended periods of low fertility without recovery, fertility is projected to remain at low levels. This probabilistic approach, informed on the country's demographic experience and on that of all low fertility nations, does not necessarily lead to convergence.

The assumptions for estimates of mortality change less over time. The computation of age-sex survival probabilities are based on Coale and Demeny regional model life tables, or the national life table if reliable. In the 1970 and 1980 Revisions, quinquennial gains are expected, declining with the lengthening of $\mathrm{e}_{0}$. In 1970, the maximum $\mathrm{e}_{0}$ is 68.2 for the sexes combined (3.5 years difference between men and women). In the 1980 Revision, geographical differences are also considered, and for countries with the highest life expectancies, the maximum forecasted $\mathrm{e}_{0}$ is 73.5 for men and 80 for women. The method adopted for the 1990 and 2000 Revisions is analogous but takes into account regional differences occurring in previous years. In developed countries, the expected gains will diminish, life expectancy will reach very high levels, and differences among countries will continue to narrow. According to the 2000 Revision, in Australia and New Zealand, North America, and in Northern, Western, and Southern Europe in 20452050, $\mathrm{e}_{0}$ will vary between 81.9 and 83.5 years, the only exception being Eastern 
Europe, with economies in transition, where $\mathrm{e}_{0}$ remains below 80 . For low mortality countries, a sigma-convergence assumption is undeniable, with the exception of Eastern European countries in the 2000 Revision.

In 2017, the general hypothesis is again one of a continuous and generalized increase in life expectancy. Through a Bayesian hierarchical model, gains in life expectancy are estimated based on country specific experiences in 1950-2015, together with average global trends. For low mortality countries, the double-logistic function incorporated into the model forecasts decreasing gains, which converge towards asymptotic values of increase in post-transition years, and a narrowing sex gap until female life expectancy is set equal to 86 years, then modeled as constant. A convergence in gains is consequently assumed, although future life expectancies will maintain asymptotically constant distances, without a clear sigma-convergence among the different countries.

UNPD experts have tended to be very cautious with regard to migration, usually projecting for several 5-year periods the current statistics in absolute value, and only for a select number of countries. For the first time in 2017 an effort was made to account for the complexity of the phenomenon. The Revision of this year remarks, "Where migration flows have historically been small and have had little net impact on the demography of a country, adopting the assumption that migration will remain constant throughout most of the projection period is usually acceptable. In situations where migration flows are a dominant factor in demographic change, more attention is needed." (UN 2017: 29). Thus some distinctions are made according to either the motivation for migration or the specificity of certain situations. The Revision considers both international migration flows and refugee movements. With regard to the former, it is assumed that recent levels (in absolute values), if stable, would continue until 2045-2050. In terms of refugees, it is assumed that the latter will return to their country of origin within one or two projection periods, i.e., within 5-10 years (UN 2017). After 2050, UNPD experts expect that net migration will gradually decline and reach $50 \%$ of the projected level of 2045-2050 by 20952100. However, they also admit that "the assumption is unlikely to be realized but represents a compromise between the difficulty of predicting the levels of immigration or emigration for each country of the world over such a far horizon, and the recognition that net migration is unlikely to reach zero in individual countries." (UN 2017: 30).

In terms of net migration, UN experts forecast large variability until 20452050, and then a sigma-convergence during the second half of the century. Yet they are aware that - given the present conditions - full convergence is not seriously predictable. In the new 2019 Revision (published just as we finish the writing of this chapter), the idea of convergence toward a 0-migration world is also abandoned. ${ }^{3}$

\footnotetext{
${ }^{3}$ The UN Population Division published its 2019 revision during the writing of this chapter. Since the methodology used in the new forecasts perfectly follows that of 2017, and the experiences of just a few countries have been updated, our results are not significantly affected. A comparison with the more and the less developed countries, respectively, shows that the differences in the birth and mortality forecasts are very limited. The most notable change concerns the hypothesis on
} 
This shift reflects another "cultural change" within the UNPD (and demography as well), where migrations are not considered "accidents" or "disturbance factors," but rather structural components of complex demographic dynamics.

\subsubsection{The Weak Convergence Hypothesis in the UN World Population Prospects, 2017 Revision}

Beyond the methodological improvements described above, when the UNPD forecasts the population dynamics of post-transitional countries, it assumes - more or less explicitly - a hypothesis of weak convergence, as we show here. ${ }^{4}$

To this regard, consider the 112 countries around the world where, according to the 2017 Revision, the total fertility rate was below 2.5 in 2010-2015. The World Population Prospects (2017) suggest that during the twenty-first century, these countries will converge to a sort of quasi-stable population with declining mortality, constant TFR of 1.8 , net migration rate around $+0.2 \%$, and natural growth rate around $-3 \% .^{5}$ In addition, fertility and migration - in just a few decades - are projected to be similar in all of these 112 countries, while mortality - continuing its declining trend - should also see decreasing variability (Table 4.1 and Fig. 4.1).

\subsection{Data and Methods}

Data for this study rely on estimates and forecasts from the World Population Prospects Revisions produced by the UN Population Division in 1980, 1990,

migration: in the 2019 Revision, after 2050 migrations are kept constant at the value of 2045-2050 and are not halved, as projected in the 2017 Revision. Consequently, results on migration are the same in the 2017 and 2019 Revisions up until 2045-2050.

${ }^{4}$ If the UNPD demographic forecasts for all countries are considered, including those that had not completed the demographic transition by 2017 , beta-convergence proceeds at full speed, because it is assumed that - within a few decades - TFR will be less than 2.5 and $\mathrm{e}_{0}$ more than 70 in almost all countries of the world. Thus, the UNPD supposes beta-convergence in considering all the countries of the world, while the sigma-convergence manifests among the countries that have completed the demographic transition.

${ }^{5}$ The concept of a quasi-stable population was introduced by Bourgeois-Pichat (1994) to model the populations that during the second half of the twentieth century maintained high levels of fertility while experiencing rapid change in their age structures due to declines in infant and youth mortality; whereas the effect of migration on population age-structure and trends are considered negligible. Now - according to the UN Population Prospects - quasi-stability would be determined by a constant fertility rate around 1.8 , and by a continuous decrease in over-50 mortality, with a consequent progressive population aging. 
Table 4.1 UN 2017 Revision of World Population Prospects for the 112 countries with TFR $\leq 2.5$ in 2010-2015. Number of countries with different values for four demographic indicators

\begin{tabular}{|c|c|c|c|c|c|}
\hline & 2010-2015 & 2030-2035 & 2050-2055 & 2070-2075 & 2090-2095 \\
\hline Total fertility rate & \multicolumn{5}{|c|}{ Number of countries } \\
\hline $1.01-1.25$ & 5 & 0 & 0 & 0 & 0 \\
\hline $1.26-1.50$ & 22 & 9 & 1 & 1 & 1 \\
\hline $1.51-1.75$ & 22 & 47 & 58 & 45 & 13 \\
\hline $1.76-2.00$ & 26 & 49 & 53 & 66 & 98 \\
\hline $2.01-2.25$ & 20 & 7 & 0 & 0 & 0 \\
\hline $2.26-2.50$ & 17 & 0 & 0 & 0 & 0 \\
\hline Life expectancy at birth & \multicolumn{5}{|c|}{ Number of countries } \\
\hline $65.1-70.0$ & 5 & 1 & 0 & 0 & 0 \\
\hline $70.1-75.0$ & 35 & 13 & 3 & 1 & 0 \\
\hline $75.1-80.0$ & 41 & 45 & 19 & 9 & 2 \\
\hline $80.1-85.0$ & 31 & 50 & 49 & 37 & 19 \\
\hline $85.1-90.0$ & 0 & 3 & 41 & 55 & 52 \\
\hline $90.1-95.0$ & 0 & 0 & 0 & 10 & 39 \\
\hline Net migration rate (per thousand) & \multicolumn{5}{|c|}{ Number of countries } \\
\hline$\leq-3.0$ & 24 & 6 & 5 & 4 & 3 \\
\hline$-2.9--1.0$ & 18 & 15 & 14 & 14 & 13 \\
\hline$-0.9-1.0$ & 30 & 57 & 58 & 65 & 72 \\
\hline $1.1-3.0$ & 12 & 21 & 24 & 25 & 24 \\
\hline$>3.0$ & 28 & 13 & 11 & 4 & 0 \\
\hline $\begin{array}{l}\text { Natural growth rate (per } \\
\text { thousand) }\end{array}$ & \multicolumn{5}{|c|}{ Number of countries } \\
\hline$\leq-7.5$ & 0 & 1 & 3 & 6 & 6 \\
\hline$-7.4--2.5$ & 7 & 22 & 45 & 56 & 69 \\
\hline$-2.4-2.5$ & 30 & 37 & 53 & 50 & 37 \\
\hline $2.6-7.5$ & 29 & 43 & 11 & 0 & 0 \\
\hline $7.6-12.5$ & 28 & 9 & 0 & 0 & 0 \\
\hline$>12.5$ & 18 & 0 & 0 & 0 & 0 \\
\hline TOTAL & 112 & 112 & 112 & 112 & 112 \\
\hline
\end{tabular}

Source: Authors' calculation on data from the UN Population Division. World Population Prospects, 2017 Revision

2000, and 2017. During the period 1975-1985, 38 countries had already reached a TFR $<2$. . $^{6}$ This group comprised virtually all the European nations including

\footnotetext{
${ }^{6}$ The 38 countries are: North-Central Europe excluding German speaking countries (Belgium, Denmark, Finland, France, Iceland, Netherlands, Norway, Sweden); English speaking countries (UK, Canada, USA, Australia, New Zealand); German speaking countries (Austria, Germany, Luxembourg, Switzerland); the former Socialist countries excluding the Balkans (Bulgaria, Czechoslovakia, Hungary, Poland, Romania, USSR); Southern Europe including the Balkans (Cyprus, Greece, Italy, Malta, Portugal, Spain, Yugoslavia); East Asia (Hong Kong, Japan, Singapore, South Korea); and the Caribbean (Barbados, Cuba, Martinique, Puerto Rico).
} 
A. Total fertility rate

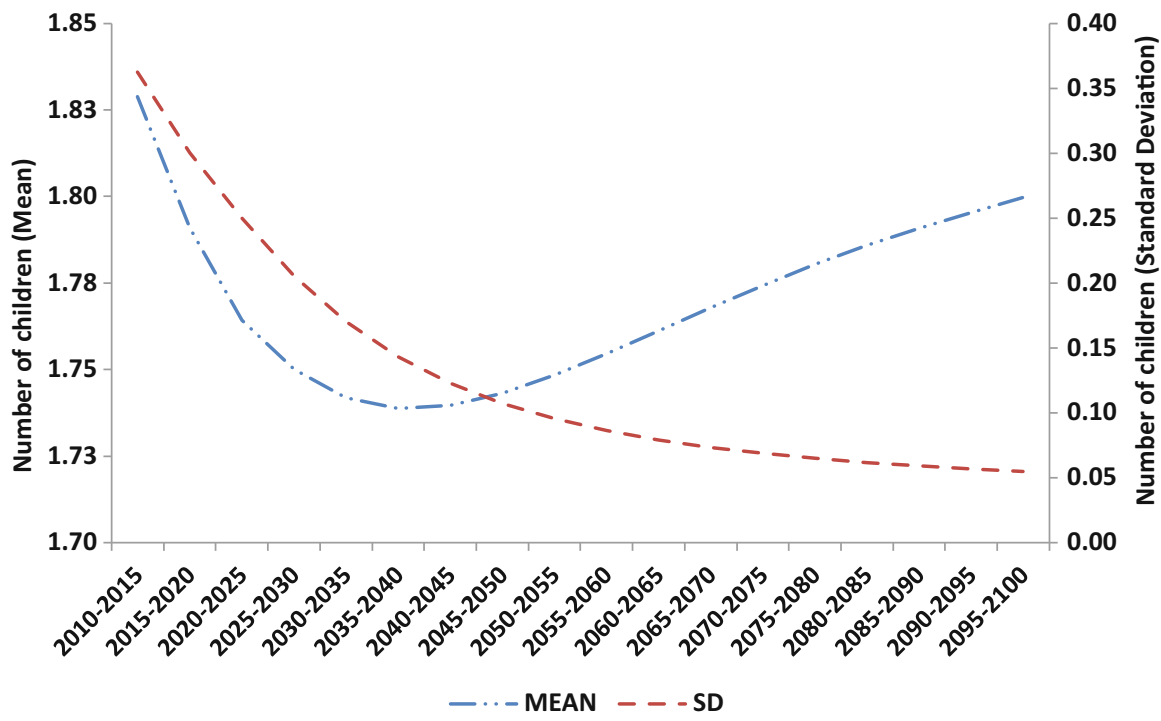

\section{B. Life expectancy at birth}

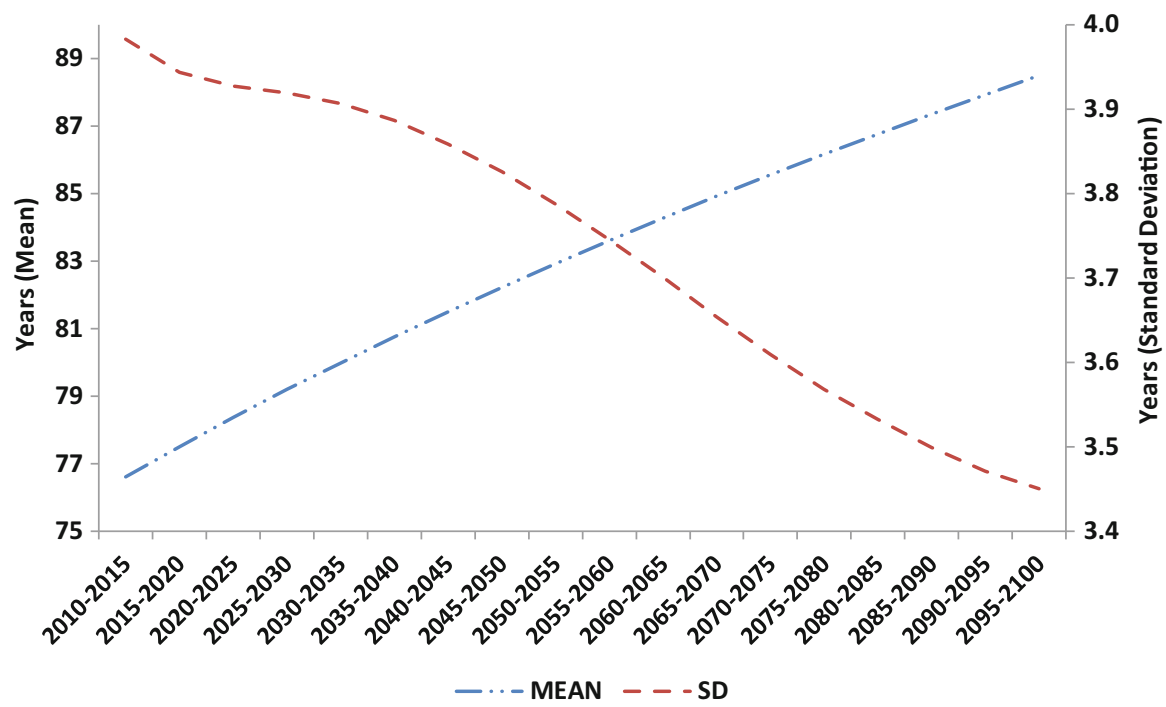

Fig. 4.1 Simple mean and standard deviation of four demographic indicators. UN Population Prospects for the 112 countries where TFR $\leq 2.5$ in 2010-2015. (a) Total fertility rate, (b) Life expectancy at birth, (c) Net migration rate (per thousand), (d) Natural growth rate (per thousand). (Source: Authors' calculation on data from the UN Population Division. World Population Prospects, 2017 Revision) 
C. Net migration rate (per thousand)
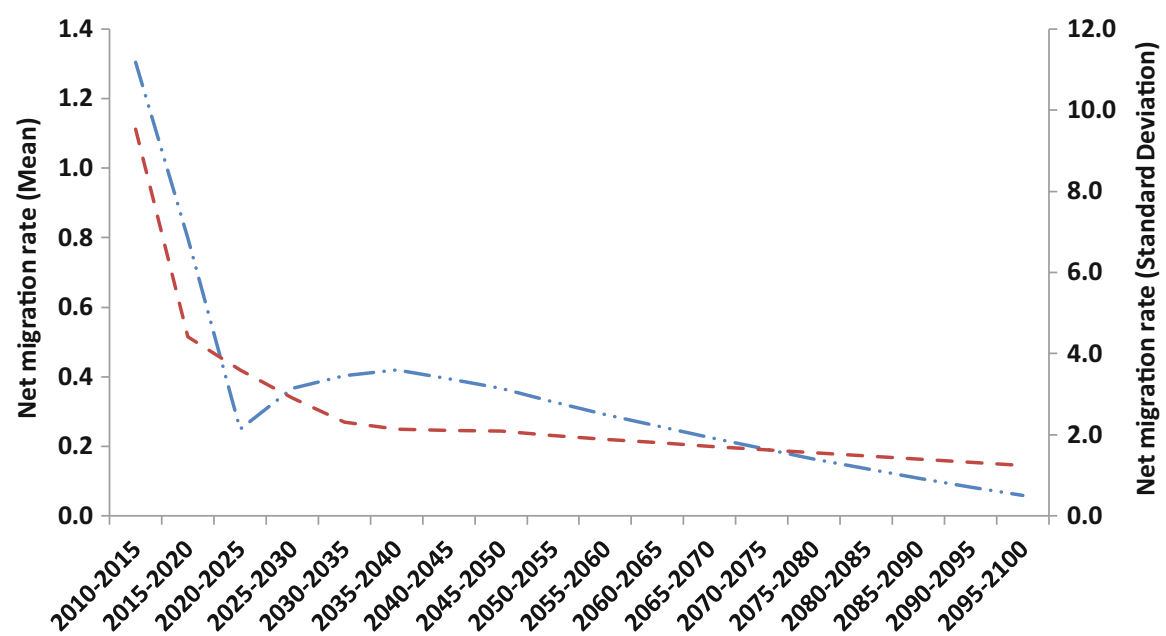

$$
-\cdots-\text { MEAN }---S D
$$

D. Natural growth rate (per thousand)

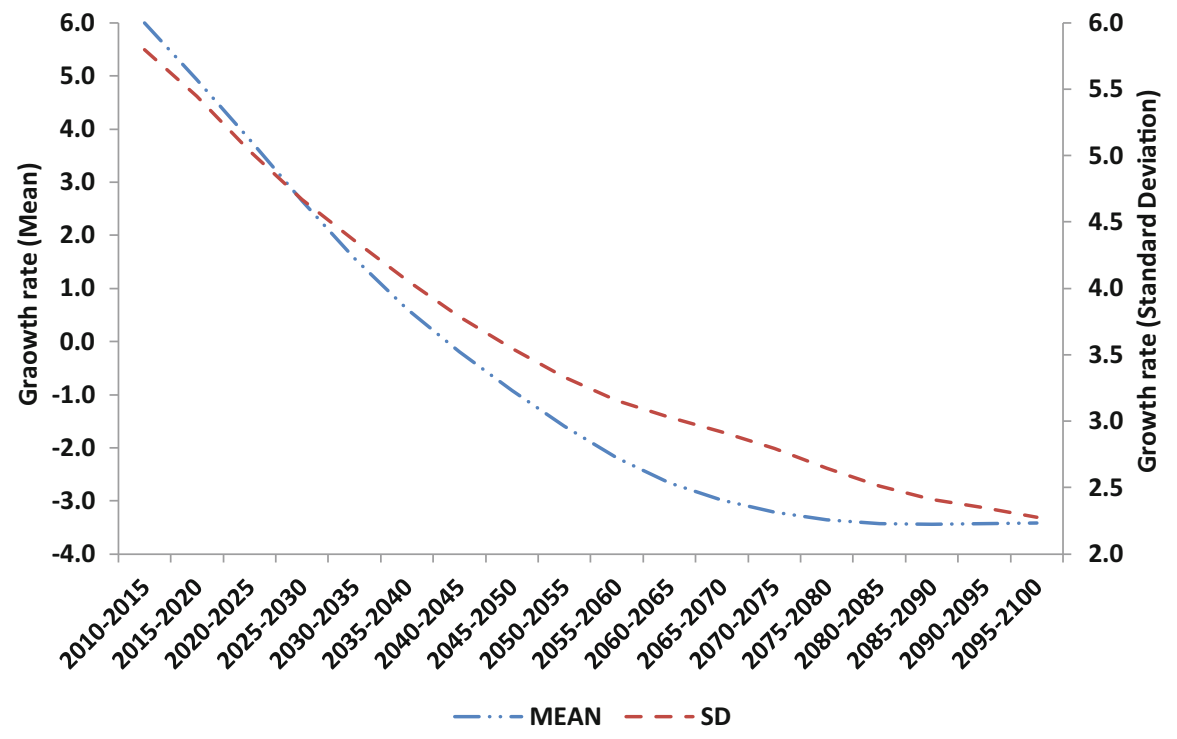

Fig. 4.1 (continued) 
Cyprus, with the exception of Albania and Ireland, where the TFR was higher than 2.5 during this time. We do not consider here very small countries and autonomous islands. In order to allow for comparisons before and after the fall of the Iron Curtain, we consider Germany in its post-1989 borders, Yugoslavia, Czechoslovakia, and USSR in their pre-1989 borders. The 38 countries also include six North American states (Canada, USA, Barbados, Cuba, Martinique, and Puerto Rico), four Asian states (South Korea, Japan, Singapore, and Hong Kong), as well as Australia and New Zealand, whereas no African nations had such low fertility in the decade of 1975-1985.

We examine three fundamental demographic forecast indicators: the total fertility rate (TFR), the life expectancy at birth $\left(\mathrm{e}_{0}\right)$, and the net migration rate (NMR), defined as the number of immigrants minus the number of emigrants over a period, divided by the person-years lived by the population of the receiving country over that period. We consider TFR, $\mathrm{e}_{0}$, and NMR for the above 38 countries, comparing the actual levels reported in the 2017 Revision for the period 1980-2015 with the World Population Prospects elaborated in 1980, 1990, and 2000. We also compare the forecasted population growth rate $r$ (a measure of population change that is strictly determined by the estimates of fertility, mortality, and migration), with the actual statistics. Rather than document the "miscalculations" of our colleagues - indeed, it would have been impossible to predict certain historical turning points such as the fall of the Berlin Wall or the collapse of the Lehman Brothers, and their demographic consequences - we aim to understand the extent to which the convergence paradigm has guided forecasters. Thus far we have seen that this hypothesis continues to prevail among those who attempt the challenge of projecting future population trends.

For each World Population Prospects Revision and indicator, we calculate the simple mean and the standard deviation (SD) of the 38 countries, for every 5-year interval between 1980-1985 and 2010-2015. An alternative procedure would have been to calculate the median and the interquartile difference, measures that have the advantage of not being affected by extreme values. While the ratio between the interquartile range and the median would be more robust, previous work (Billari 2018, p. 20, Fig. 2.3) has shown that results given by the two indexes are consistent. Median and interquartile differences are available on request. Moreover, we do not weight the country means according to population size, because we focus specifically on differences between countries as separate entities, as opposed to the proportion of world population they represent.

Finally, we use an analysis of variance (ANOVA) method to assess the proportion of total variability for the four indicators $\left(\mathrm{e}_{0}, \mathrm{TFR}, \mathrm{NMR}, \mathrm{r}\right)$ explained by belonging to a given geographical cluster. Countries are grouped into seven clusters, based broadly on the United Nations Regional Groups, and a consideration of fertility trends (see also note 6). The idea being that if a process of convergence was at work during the period 1980-2017, then the differences between these country groups should be less and less relevant. More specifically, the proportion of variance between the groups' averages for the identified demographic indicators should progressively lessen. 


\subsection{Results: The Lack of Weak Convergence}

\subsubsection{Fertility}

The UN Prospects Revisions of 1980 and 1990 suggest that countries having completed the fertility transition will quickly converge towards similar TFRs around 1.8-1.9. Figure 4.2 shows that over the last 30 years, for post-transitional countries, this convergence has not occurred. The SD between the TFRs of the 38 countries that had already reached a TFR of less than 2.5 during the period $1975-1985$, declines slowly between 1975-1980 and 2010-2015, while the coefficient of variation
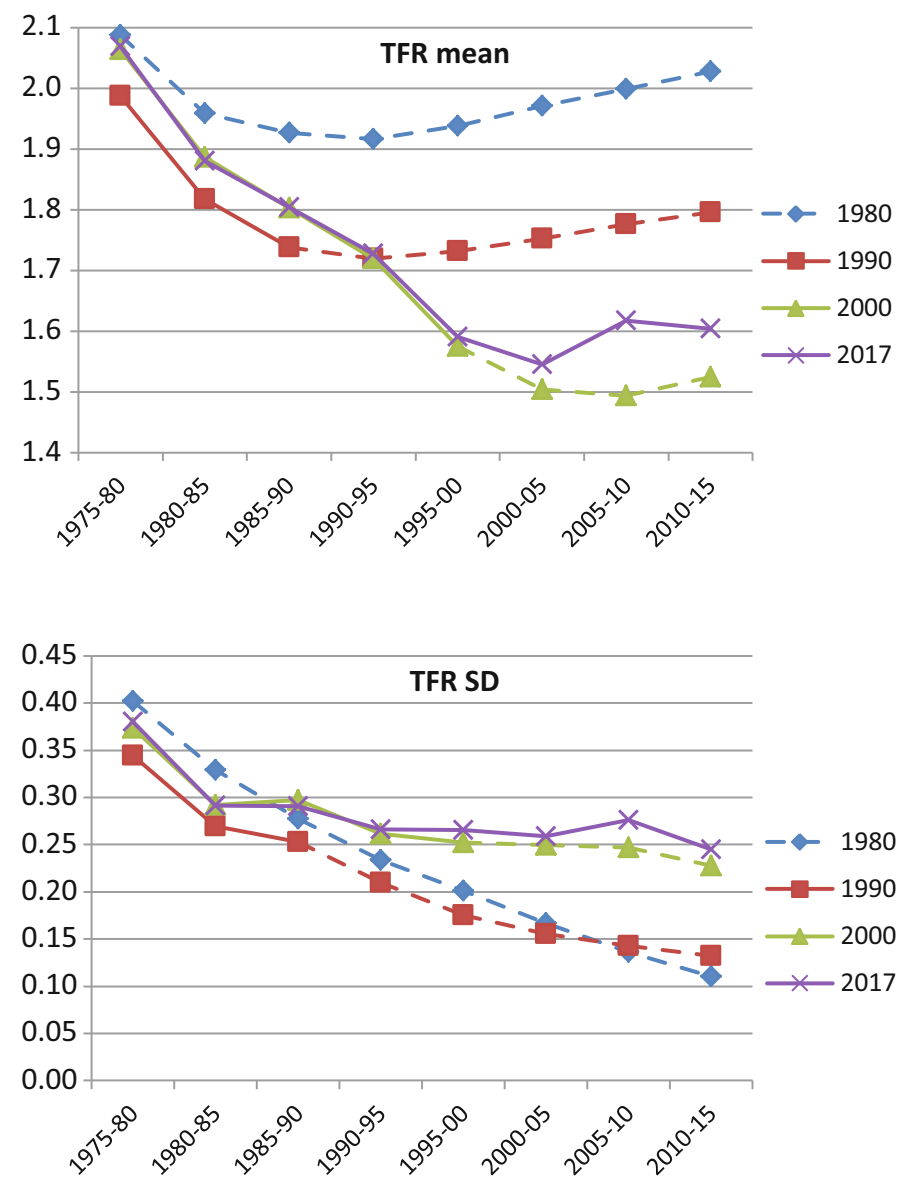

Fig. 4.2 Trends and variation in TFR among the 38 countries where TFR $<2.5$ before 1985 . UN Population Division: 1980, 1990, and 2000 Population Prospects, and 2017 estimation. (Source: Authors' calculation on data from the UN Population Division. World Population Prospects) 
(SD/mean) drops only in the first 5-year period, and then remains almost constant between 1980 and 2015 .

The level of the variability in fertility thus basically remains steady between 1980 and 2015, while according to the UN forecasts of 1980 and 1990 it should have lessened. This situation changes when comparing actual trends with the 2000 forecasts. In this case, the Population Division has accurately predicted the average fertility trends and - mainly - the variability and lack of convergence among the 38 countries. However, in light of the correctness of this forecast, it is difficult to understand why, for the following years and decades, a convergence in fertility among post-transitional countries (Fig. 4.1a and Table 4.1) should be seen as inevitable.

\subsubsection{Mortality}

The 1980 World Population Prospects was unsuccessful in predicting either the spectacular increase in life expectancy ( 8 years of life gained in just 35 years) or the persistence of profound differences between countries (Fig. 4.3). Even if the 1990 World Population Prospects predicted a convergence that would not occur, it was more cautious in suggesting further increases in average length of life. Meanwhile, the 2000 World Population Prospects - confirming the pace of $\mathrm{e}_{0}$ increase expected in the 1990 World Population Prospects for the early years of the new century - significantly underestimated (by 2 years) the actual increase in survival, but correctly predicted the lack of convergence between countries. Again, given these results, the progressive convergence of $\mathrm{e}_{0}$ values expected in the coming decades in the UNPD forecasts of 2017 and 2019 (Fig. 4.1b and Table 4.1) should perhaps be reconsidered.

\subsubsection{Migration}

Migration rates are by far the most difficult population parameters to forecast as they are more strictly related to largely unpredictable external shocks, such as economic downturns. As already seen for TFR, neither the 1980 nor 1990 World Population Prospects predicted the extent or variability of the NMR (Net Migration Rate) in the first 15 years of the new century (Fig. 4.4). In fact, not even the 2000 forecasts were able to envisage what has actually happened. While the immigration boom of the first decade of the new century and the further increase in the cross-country differences was recorded by the data collected in 2017, such shifts were entirely unforeseen in the projections made 17 years earlier. 

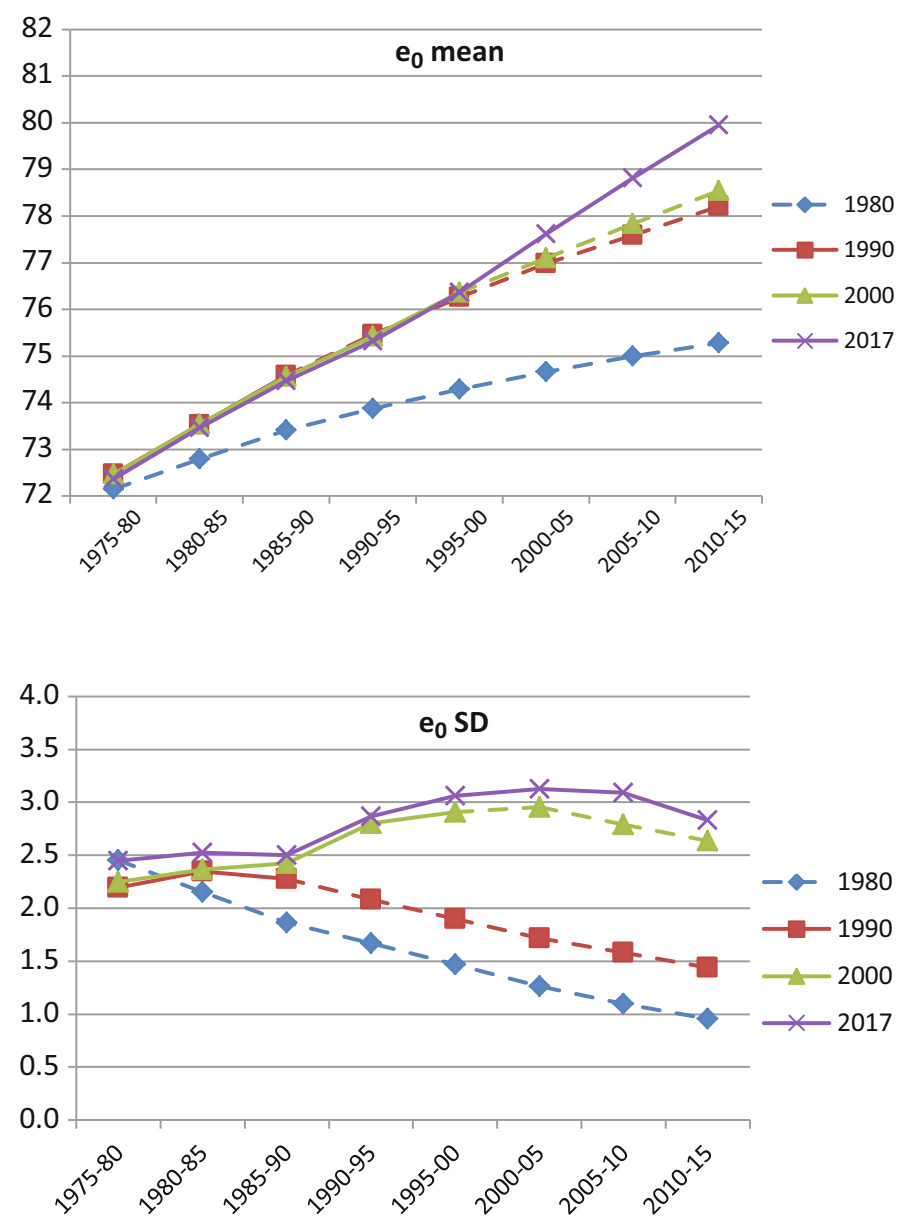

Fig. 4.3 Trends and variation of $\mathrm{e}_{0}$ among the 38 countries where TFR $<2.5$ before 1985 . UN Population Division: 1980, 1990, and 2000 Population Prospects, and estimation of 2017. (Source: Authors' calculation on data from the UN Population Division. World Population Prospects)

\subsubsection{Growth Rate}

The combination of prediction errors of fertility, mortality, and migration significantly impacts forecasts of the population growth rate $\mathrm{r}$ (Fig. 4.5). The World Population Prospects of 1980, 1990, and 2000 concur in suggesting, for the first years of the twenty-first century, rapidly declining population growth rates. Yet, in 2000-2015, the growth of the entire population of the 38 post-transitional countries under analysis never dropped below $4 \%$. This is due in part to the rise in survival rates - with consequent greater growth in the number of elderly - but above all to the increase in the net migration rate, resulting in more young adults and, to some 

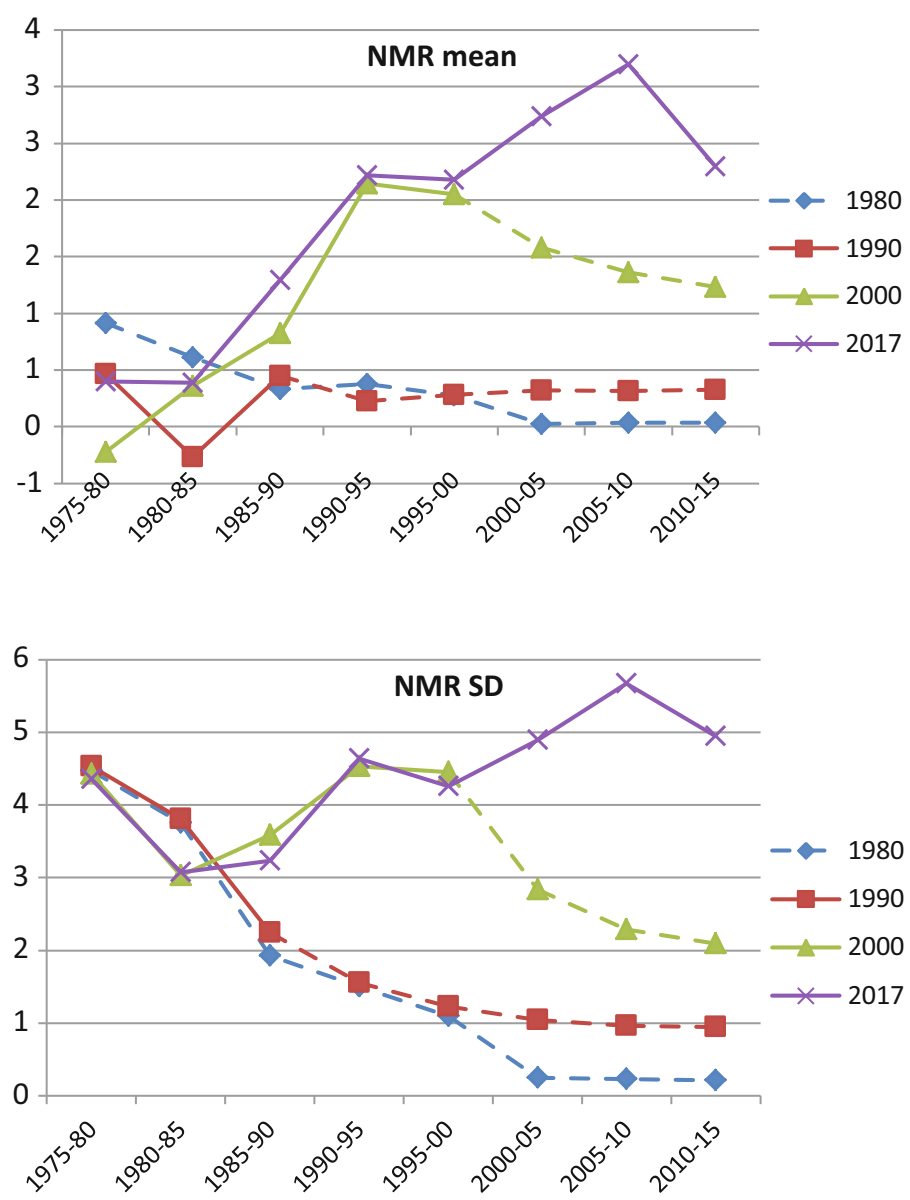

Fig. 4.4 Trends and variation of NMR (per thousand) among the 38 countries where TFR $<2.5$ before 1985. UN Population Division: 1980, 1990, and 2000 Population Prospects, and estimation of 2017. (Source: Authors' calculation on data from the UN Population Division. World Population Prospects)

extent, children. The forecasts of $\mathrm{r}$ variability also proved to be incorrect. Contrary to that suggested by the World Population Prospects of 1980, 1990, and 2000, during the first 15 years of the new century the variability of $r$ among the 38 countries saw higher levels than those observed during 1975-1990.

This divergence is largely due to the extremely different demography of the excommunist bloc (i.e., negative migration rates, low fertility, and stagnation or even decrease in life expectancy) compared to that of Northern Europe and the Overseas English-speaking countries (i.e., positive migration rates, less depressed fertility, and continuous rise in life expectancy). For example, in the quarter century of 1990- 

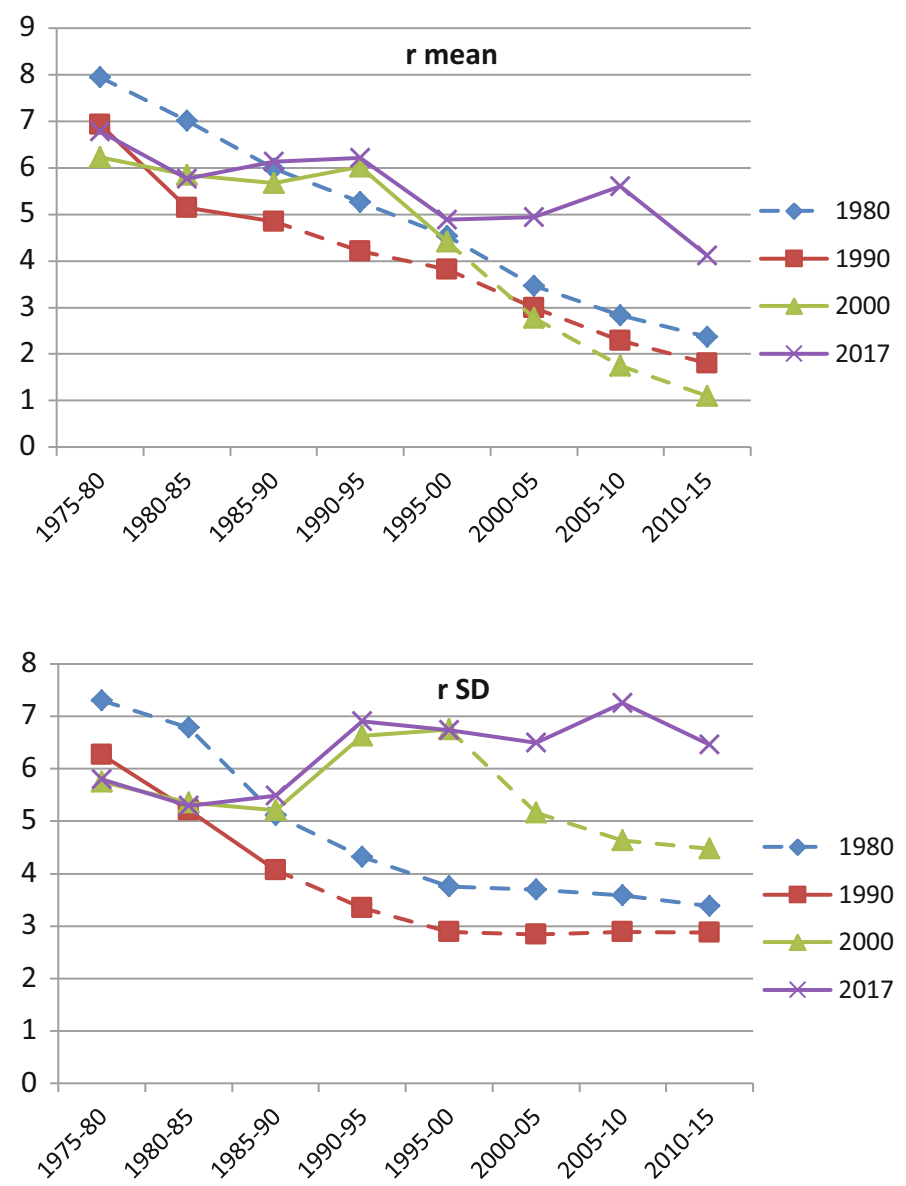

Fig. 4.5 Trends and variation of growth rate $r$ (per thousand) among the 38 countries where TFR $<2.5$ before 1985. UN Population Division: 1980, 1990, and 2000 Population Prospects, and estimation of 2017. (Source: Authors' calculation on data from the UN Population Division. World Population Prospects)

2015 the population growth rate was $5.3 \%$ in the USA compared to $-0.2 \%$ in the former USSR.

\subsubsection{The ANOVA Analysis}

Table 4.2 reports the analysis of variance (ANOVA) results carried out on the estimated and forecasted values for the four indicators $\left(e_{0}, T F R, N M R, r\right)$. As explained in Sect. 4.3, if there would have been convergence, then the share of 
variance across the seven country groups, as a percentage of the total variance, should have been decreasing. In the 2017 row for each indicator, the ANOVA is based on actual data, taken from the estimates for 1975-2015 published in the 2017 Revision. The table largely confirms the divergence in demographic trends. For mortality specifically, the proportion of variance between the seven groups on the whole variance substantially increases from $40 \%$ to $70 \%$ in the period from 1975-1980 to 2010-2015. For fertility, the trend is U-shaped, as the proportion of variance between groups decreases up until 1995 and then later increases up to around $80 \%$. For migration, the proportion of variance between groups is less systematic, rising and falling from 1975 to 2000 and then subsequently increasing up to 53\% in 2010-2015. These results show that the differences between the groups for the three indicators do not, in fact, narrow over time. Quite the opposite is true, against the hypothesis of convergence.

The other rows in Table 4.2 present the ANOVA outcomes based on the estimates and forecasts for the three indicators in 1980, 1990, and 2000. ${ }^{7}$ The forecast results (in italics) share the characteristic of holding the variability explained by the groups nearly invariant on the value of the last 5 years observed (Table 4.2). Therefore, even if the 1980 and 1990 Revisions assumed drastic reduction in the variability of the three indicators among the 38 countries, the geographical differences should have remained constant, in relative terms. The same happens with the 2000 Revision with regard to the NMR. However, things are different in the 2000 edition in terms of TFR and $e_{0}$ forecasts for the 2000-2015 period: as seen previously in Figs. 4.2 and 4.3 , the projection of variability among the 38 countries remains high, substantially similar to that which actually occurred. However, while for $\mathrm{e}_{0}$, variability between the seven groups is correctly predicted as high and is in line with actual $\mathrm{e}_{0}$, for TFR, the polarization of the single countries around the averages of the groups to which they belong was not foreseen.

The main lesson of this analysis is that - after the end of the Demographic Transition - not only does the variability between these countries not decrease, neither does the variability between groups of countries. Again, the notion of weak convergence is not reflected in the actual data: fertility, mortality, and migration rates do not move towards similar and undistinguishable values among the countries that have already completed the Demographic Transition.

\footnotetext{
${ }^{7}$ Percentages of variance for TFR, NMR and $\mathrm{r}$ in 1995-2000, in the rows of prospects 2000 and 2017, are surprisingly different. An explanation is different estimates of empirical indicators mainly in Cyprus, Hong Kong, Barbados, Cuba, and Martinique, based on partial availability of updated recent data.
} 


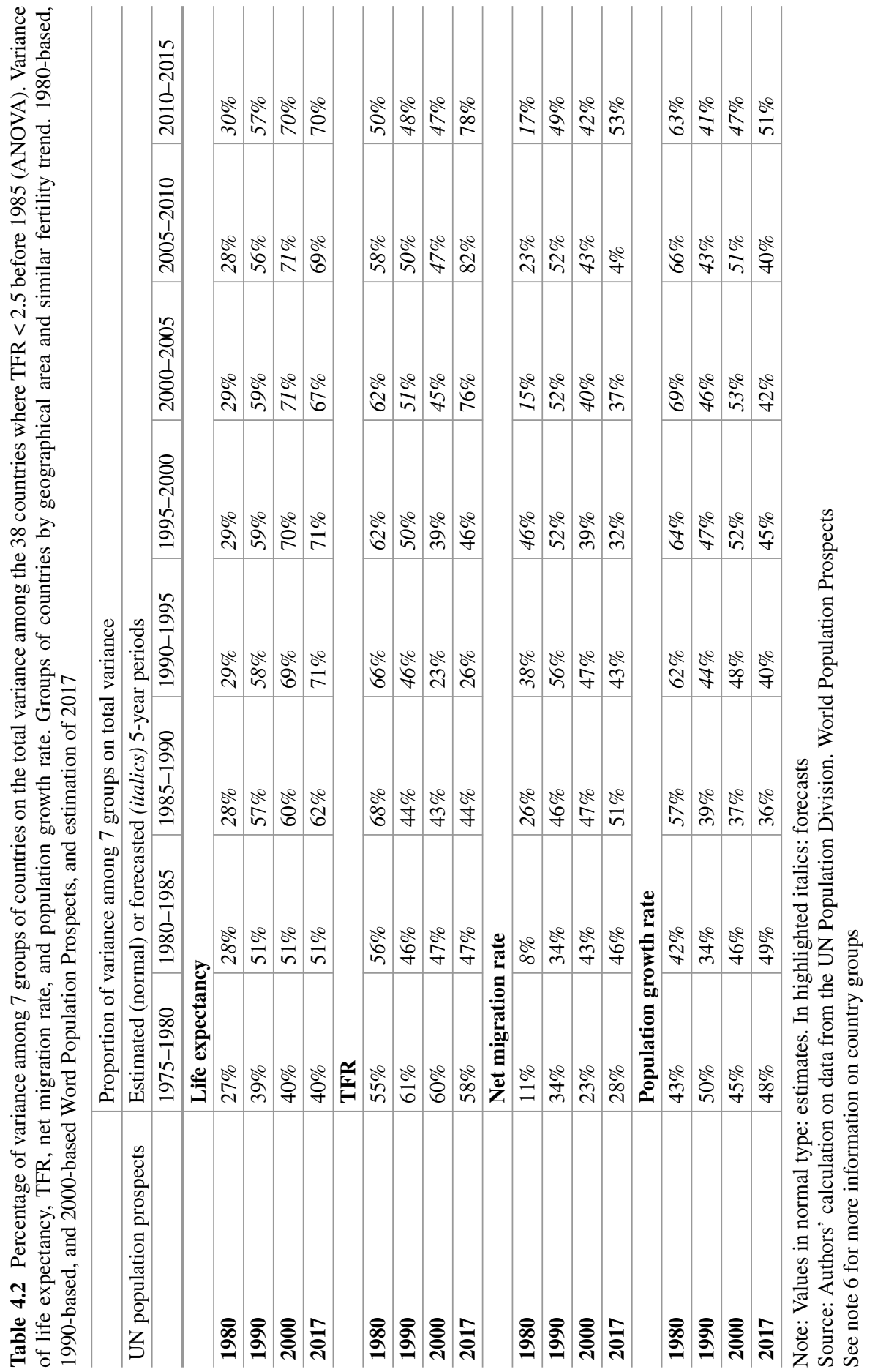




\subsection{Concluding Remarks}

The strong paradigm of the Demographic Transition has provided an exceptionally useful tool for describing a common path of demographic change among countries, and their remarkable convergence over time from a regime of high mortality and fertility to a new regime of low fertility and mortality. This well-known pattern drove forecasters to project mortality and fertility in a shared direction of transformation as modernization and economic development spread around the world.

In this chapter, however, we show that the idea of a general convergence also seems to inform the hypotheses and/or the outcome of population projections elaborated by UNPD experts for countries that have already completed their demographic transition, into what we call a "weak convergence." We demonstrate that this idea is not supported by empirical evidence: there are no unequivocal signs of a general convergence in fertility, mortality, and net migration towards common values for the 38 countries that had a TFR $<2.5$ before 1985 .

While this lack of convergence was correctly predicted in the 2000 Revision of World Population Prospects for mortality and fertility (but not for migration) in the period 2000-2015, the idea of convergence nonetheless seems to inform the hypotheses of UNPD forecasters in subsequent Revisions. In addition, we find that the differences between groups of countries that we identified as homogeneous actually increase between 2000 and 2015, showing a marked characterization of demographic behavior by geographical area.

In light of these results, it is difficult to understand why in the following period of 2015-2050 we should expect the 112 countries with a TFR below 2.5 children per woman in 2015 to converge towards similar values, as suggested by the 2017 Revision of World Population Prospects (Table 4.1 and Fig. 4.1). Further research is necessary to identify new regularities that can aid forecasters who have been "abandoned" by the demographic transition paradigm. The challenge is far from small as these 112 countries are even more differentiated in terms of regional characteristics, institutional settings, level of economic development, and value adherence than the initial 38 .

Acknowledgement We acknowledge the contribution of the Project PRIN 2017 (n. 2017W5B55Y_003), titled “The Great Demographic Recession” (GDR).

\section{References}

Alho, J. M., \& Spencer, B. D. (1985). Uncertain population forecasting. Journal of the American Statistical Association, 80(390), 306-314.

Anderson, T., \& Kohler, H.-P. (2015). Low fertility, socioeconomic development and gender equity. Population and Development Review, 41(3), 381-407.

Barro, R. J., \& Sala-i-Martin, X. (1992). Convergence. The Journal of Political Economy, 100, 223-251. 
Barro, R. J., Sala-I-Martin, X., Blanchard, O. J., \& Hall, R. E. (1991). Convergence across states and regions. Brookings Papers on Economic Activity, 1991, 107-182.

Basten, S., Sobotka, T., \& Zeman, K. (2014). Future fertility in low fertility countries. In W. Lutz, W. P. Butz, \& K. C. Samir (Eds.), World population and human capital in the twenty-first century. Oxford: Oxford University Press.

Bengtsson, T., Keilman, N., Alho, J. M., Christensen, K., Palmer, E., \& Vaupel, J. W. (2019). Introduction. In T. Bengtsson \& N. Keilman (Eds.), Old and new perspectives on mortality forecasting (Demographic research monographs (A Series of the Max Planck Institute for Demographic Research)). Cham: Springer.

Billari, F. C. (2018). Chapter 2: A "great divergence" in fertility? In D. L. Poston Jr. (Ed.), Low fertility and regimes and demographic and societal change. Cham: Springer International Publishing.

Bloom, D. E., \& Canning, D. (2007). Mortality traps and the dynamics of health transitions. Proceedings of the National Academy of Sciences, 104, 16044-16049.

Bourgeois-Pichat, J. (1994). La Dynamique des populations. Populations stables semi-stables et quasi stables (Travaux et Documents). Paris: INED.

Calot, G., \& Chesnais, J. C. (1978). La prevision démographique. In A.-C. Dans (Ed.), Decouflé Traité élémentaire de prevision et de prospective. Paris: PUF.

Casterline, J. B. (2001). The pace of fertility transition: National patterns in the second half of the twentieth century. Population and Development Review, 27(Supplement), 17-52.

Clark, R. (2011). World health inequality: Convergence, divergence and development. Social Science and Medicine, 72, 617-624.

Crenshaw, E. M., Christenson, M., \& Oakey, D. R. (2000). Demographic transition in ecological focus. American Sociological Review, 65, 371-391.

Dorius, S. F. (2008). Global demographic convergence? A reconsideration of changing intercountry inequality in fertility. Population and Development Review, 34(3), 519-537.

Goesling, B., \& Firebaugh, G. (2004). The trend in international health inequality. Population and Development Review, 30, 131-146.

Henry, L. (1987). Perspectives et prévision. In Les projections démographiques. Actes du VIIIe Colloque National de Démographie (Tome 1) (Traveaux et Documents Cahier no. 116). Paris: Presses Universitaires de France.

Keilman, N. (1997). Ex-post errors in official population forecasts in industrialized countries. Journal of Official Statistics, 13, 245-277.

Keilman, N. (1998). How accurate are the United Nations world population projections? Population and Development Review, 24(Supplement), 15-41.

Keilman, N. (2000). Précision et incertitudes des prévisions nationales de population. In C. Wattelar \& J. Duchêne (Eds.), Le défi de l'incertitude: Nouvelles approches en perspectives et prospective démographiques. Actes de la Chaire Quetelet 1995 (pp. 33-67). Louvain-la-Neuve: Academia-Bruylant/L'Harmattan.

Keilman, N. (2001). Data quality and accuracy of United Nations population projections, 1950-95. Population Studies, 55(2), 149-164.

Keilman, N. (2019). Erroneous population forecast. In T. Bengtsson \& N. Keilman (Eds.), Old and new perspectives on mortality forecasting, demographic research monographs (A series of the Max Planck Institute for Demographic Research). Cham: Springer.

Keilman, N., \& Pham, D. Q. (2004). Empirical errors and predicted errors in fertility, mortality and migration forecasts in the European economic area (Discussion Paper 386). Oslo: Statistics Norway.

Keyfitz, N. (1981). The limits of population forecasting. Population and Development Review, 7, 579-593.

Kirk, D. (1996). Demographic transition theory. Population Studies, 50(3), 361-387.

Kohler, H.-P., Billari, F., \& Ortega, J. A. (2002). The emergence of lowest-Loe fertility in Europe during the 1990s. Population and Development Review, 28(4), 641-680.

Lee, R. D. (1998). Probabilistic approaches to population forecasting. Population and Development Review, 24, 156-190. 
Livi Bacci, M. (2012). A concise history of world population. Chichester: Wiley-Blackwell.

Lutz, W., Skirbekk, V., \& Testa, M. R. (2006). The low-fertility trap hypothesis: Forces that may lead to further postponement and fewer births in Europe. Vienna Yearbook of Population Research, 4, 167-192.

McMichael, A., McKee, M., Shkolnikov, V. M., \& Valkonen, T. (2004). Mortality trends and setbacks: Global convergence or divergence? The Lancet, 363, 1155-1159.

Moser, K., Shkolnikov, V. M., \& Leon, D. A. (2005). World mortality 1950-2000: Divergence replaces convergence from the late 1980s. Bulletin of the World Health Organization, 83(3), 202-209.

National Research Council 2000. (2000). Beyond six billion: Forecasting the world's population. Panel on population projections. In J. Bongaarts \& R. Bulatao (Eds.), Committee on population, commission on behavioral and social sciences and education. Washington, DC: National Academy Press. Available at http://books.nap.edu/books/0309069904/html/index.html.

Neumayer, E. (2004). HIV/AIDS and cross-national convergence in life expectancy. Population and Development Review, 30, 727-742.

Pflaumer, P. (1988). The accuracy of U.N. population projections. In Proceedings annual meeting American statistical association, New Orleans, August 1988. Social Statistics Section, 299304.

Preston, S. (1974). An evaluation of postwar mortality projections in Australia, Canada, Japan, New Zealand, and the United States. WHO Statistical Report, 27, 719-745.

Raftery, A. E., Li, N., Ševčíková, H., Gerland, P., \& Heilig, G. K. (2012). Bayesian probabilistic population projections for all countries. Proceedings of the National Academy of Sciences, 109(35), 13915-13921.

Raftery, A. E., Alkema, L., \& Gerland, P. (2014). Bayesian population projections for the united Nations. Statistical Science, 29, 58-68.

Reher, D. S. (1998). Family ties in Western Europe: Persistent contrasts. Population and Development Review, 24(2), 203-234.

Reher, D. S. (2004). The demographic transition revisited as a global process. Population, Space and Place, 10, 19-41.

Reher, D. S. (2011). Economic and social implications of the demographic transition. In R. D. Lee \& D. S. Reher (Eds.), Demographic transition and its consequences (Supplement to Vol. 37 of Population and Development Review). New York: Population Council.

Reher, D. R. (2019). The Aftermath of the demographic transition in the developed world: Interpreting enduring disparities in reproductive behavior. Population and Development Review. On-line, 26 June 2019. https://doi.org/10.1111/padr.12266.

Reher, D. S. (2019). The Aftermath of the demographic transition in the developed world: Interpreting enduring disparities in reproductive behaviour. Population and Development Review. On-line, 26 June 2019. https://doi.org/10.1111/padr.12266.

Rindfuss, R. R., \& Choe, M. K. (Eds.). (2015). Low and lower fertility: Variations across developed countries. Cham: Springer.

Rindfuss, R. R., \& Choe, M. K. (Eds.). (2016). Low fertility, institutions and their policies: Variations across industrialized countries. Cham: Springer.

Rindfuss, R. R., Choe, M. K., \& Brauner-Otto, S. R. (2016). The emergence of two distinct fertility regimes in economically advanced countries. Population Research and Policy Review, 35(3), 287-304.

Sala-i-Martin, X. (1996). The classical approach to convergence analysis. The Economic Journal, 106, 1019-1036.

Sobotka, T. (2017). Post-transitional fertility: The role of childbearing postponement in Fuelling the shift to low and unstable fertility levels. Journal of Biosocial Science, 49(S1), S20-S45. https://doi.org/10.1017/S0021932017000323.

Sobotka, T., Matysiak, A., \& Brzozowska, Z. (2017). Gender revolution, family reversal and fertility, paper presented at IUSSP Population Conference, Cape Town, November 2017.

Stoto, M. (1983). The accuracy of population projections. Journal of the American Statistical Association, 78, 13-20. 
Thornton, A. (2001). The developmental paradigm, Reading history sideways, and family change. Demography, 38(4), 449-467.

United Nations, Department of Economic and Social Affairs, Population Division (2014). World Population Prospects: The 2012 Revision, Methodology of the United Nations Population Estimates and Projections. ESA/P/WP.235. New York: United Nations.

United Nations, Department of Economic and Social Affairs, Population Division (2017). World Population Prospects: The 2017 Revision, Methodology of the United Nations Population Estimates and Projections, Working Paper No. ESA/P/WP.250. New York: United Nations.

Wilson, C. (2001). On the scale of global demographic convergence 1950-2000. Population and Development Review, 27(1), 155-171.

Wilson, C. (2011). Understanding global demographic convergence since 1950. Population and Development Review, 37(2), 375-388. https://doi.org/10.1111/j.17284457.2011.00415.x.

Wilson, C. (2013). Thinking about post-transitional demographic regimes: A reflection. Demographic Research, 28, 1373-1388.

Open Access This chapter is licensed under the terms of the Creative Commons Attribution 4.0 International License (http://creativecommons.org/licenses/by/4.0/), which permits use, sharing, adaptation, distribution and reproduction in any medium or format, as long as you give appropriate credit to the original author(s) and the source, provide a link to the Creative Commons license and indicate if changes were made.

The images or other third party material in this chapter are included in the chapter's Creative Commons license, unless indicated otherwise in a credit line to the material. If material is not included in the chapter's Creative Commons license and your intended use is not permitted by statutory regulation or exceeds the permitted use, you will need to obtain permission directly from the copyright holder.

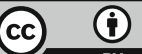

